\title{
A questão da família na perspectiva LGBTQI+
}

The Family Issue from the LGBTQI+ Perspective

José Antônio Trasferetti

Pontifícia Universidade Católica de Campinas - PUC-Campinas, Brasil

\section{Resumo}

Este texto objetiva apresentar uma reflexão sobre a família no contexto da comunidade LGBTQI+. Trata-se de compreender a diversidade de situações familiares presentes no Brasil atual. A Comunidade LGBTQI+ se insere num amplo leque de comportamentos oriundos de novas realidades socioeconômicas, políticas e tecnológicas. 0 texto aponta para a necessidade de acolhimento, acompanhamento, discernimento, educação e integração dessas famílias na sociedade civil e nas pastorais das Igrejas.

\section{Abstract}

This text intends to present a consideration about family in the environment of the LGBTQI+ community. Hereby we try to understand the diversification of family situations in Brazil nowadays. In the LGBTQI+ community there is a variety of different behaviours that has arisen from new social-economic, political and technologic conditions. The text calls for the need of a favourable reception, careful attendance, perception, guidance and integration of these families in the civil society and in the churchs.

\section{Palavras-chave}

Família.

Sociedade civil. Pastoral.

Acolhimento.

\section{Keywords}

Family. Civil society. Pastoral. Favourable reception.

\section{Introdução}

Este texto objetiva apresentar uma reflexão ético-teológico-pastoral sobre a questão da família no contexto da comunidade LGBTQIA+. Trata-se, evidentemente, de um tema vinculado às instituições civis referentes à família, escolas, Ongs, e também às Comunidades Eclesiais Missionarias. A ética teológica tem enfrentado esse tema a partir da solicitude pastoral, uma vez, que nossos pastores (párocos, administradores paroquiais, vigários 
paroquiais) estão diretamente envolvidos com pessoas e ou casais dessas comunidades. Evidentemente que o rigor doutrinal é importante, mas nosso empenho está na vida pastoral em sua dimensão de acolhimento, proteção, cuidado, educação, discernimento e, integração dessas pessoas. É preciso repensar a moral ou a ética teológica à luz do modo de fazer pastoral. Sem dúvida, essa é a grande contribuição do Papa Francisco em seu magistério.

Toda pessoa está inserida numa família (seja ela civil ou religiosamente constituída ou não). É impossível viver fora de uma família de modo que no mundo atual sempre existiu muitas formas de convivência familiar que são imprescindíveis de serem levadas em consideração no desenvolvimento de uma teologia e de uma ética teológica que corresponda aos anseios e questões da contemporaneidade. O fato de o magistério eclesial instituir uma forma de família (heterossexualidade, união afetiva, transmissão da vida, lei natural, etc.), não significa que todas as outras formas devem ser excluídas. Devemos ir a todas as ovelhas, mas, sobretudo, aquelas que estão mais vulneráveis. É preciso combater o preconceito, fruto da ignorância, que gera a violência no Brasil e no mundo. Segundo dados, o Brasil lidera o ranking de países que mais assassinam pessoas da comunidade LGBTQIA+, especialmente pessoas transexuais. A violência dispensada a este grupo no Brasil desencadeou mais de 124 assassinatos apenas nos nove primeiros meses de 2020. De todos os países da América Latina, o Brasil concentra a responsabilidade por mais de $43 \%$ da violência perpetrada contra minorias vulneráveis LGBTQIA+².

Partindo da constatação da realidade em toda sua complexidade, defendemos a necessidade de uma educação moral que permeie todos os nossos ambientes, num clima de diálogo que promova a compreensão e o bom relacionamento entre as pessoas. A atitude de acolhimento, educação, discernimento e integração são possibilidades reais que desafios os tempos

\footnotetext{
1 ZACHARIAS, R., Amoris Laetitia: Um "sim" radical à Pastoralidade da Teologia Moral. Perspectiva Teológica, Belo Horizonte, v. 53, n.1. 17-39, jan/abr. 2021.

2 JUSTO, G. Pelo $12^{\circ}$ ano consecutivo, Brasil é o país que mais mata transexuais no mundo. In: Exame, 2020, disponível em < https://exame.com/brasil/pelo-12o-ano-consecutivo-brasil-epais-que-mais-mata-transexuais-no-mundo/ > Acesso em: 16/08/2021.
} 
atuais impõe $\mathrm{e}^{3}$. O rigor da doutrina não deve desfavorecer a bondade pastoral, pelo contrário, quanto mais cristãos e missionários mais acolhedores deveremos ser. Vivemos em tempos de grandes mudanças comportamentais, que acompanhadas de outras mudanças, caracterizam a contemporaneidade como "época de mudança”. As incertezas são enormes, mas devemos procurar as luzes que o evangelho apresenta entre as sombras do nosso tempo. Tarefa difícil, exigente, mas possível em tempos desafiadores e, complexos.

\section{A comunidade LBGTQI+: o amor que se transmuda}

As nossas comunidades paroquias sempre estiveram muito atentas aos movimentos de casais, sobretudo, aos casais constituídos oficialmente no civil e no religioso. As famílias tradicionais, de caráter conservador, com seus costumes e práticas, sempre foram bem acolhidas fazendo parte intrínseca dos nossos planejamentos paroquiais. Entretanto, o Brasil e, o mundo têm sofrido profundas alterações nas formas de comportamento amoroso, sexual e afetivo. As novas circunstâncias dos tempos atuais apresentam um amplo leque de constituições familiares. As formas de namoro, noivado, acasalamento, uniões de todo tipo estão se transformando profundamente. Essas mudanças recebem influência das novas formas de capitalismo, tecnologias, redes sociais, plataformas digitais, etc. Os relacionamentos que sempre foram marcados pela conduta heterossexual, já há algum tempo tem se configurado também na forma homoafetiva.

A partir da própria experiência pessoal, pude constatar ao longo dos anos que houve um bom desenvolvimento da reflexão acerca da comunidade LGBTQIA+. Quando iniciei meus trabalhos pastorais e reflexões teológicas nesse âmbito o termo era GLS, ou seja, Gays, Lésbicas e simpatizantes. Posteriormente passou a ser usado como LGBT. Esse termo significa Lésbicas, Gays, Bissexuais, Travestis e Transexuais, sendo utilizado no Brasil desde 2008. As palavras lésbica e gay se referem a pessoas que sentem atração

${ }^{3}$ TRASFERETTI, J.A. A Lógica Inclusiva do Evangelho. In ZACHARIAS, R., CASTRO MILLEN M.I., A Moral do Papa Francisco: um projeto a partir dos descartados. Aparecida: Santuário, 2020, p. 331-355. 
sexual, física e afetiva por pessoas do mesmo gênero. A palavra Bissexual se refere a pessoa que se relaciona afetiva e sexualmente com pessoas de ambos os sexos e gêneros. Com a palavra Travesti nominam-se pessoas que nascem do sexo masculino, mas que tem sua identidade de gênero oposta ao seu sexo biológico. Quanto ao Transexual, podemos afirmar que são pessoas que não se enxergam no gênero designado no seu nascimento. E LGBTQ+? Nessa sigla, foi inserida a letra $\mathrm{Q}$, que significa Queer. É um termo inglês, que traduzindo, ao pé da letra, significa estranho. Ele engloba pessoas que se identificam com todas as orientações sexuais e gêneros, sem se encaixar em apenas um deles. As pessoas vinculadas a esses grupos têm se mobilizado em prol dos direitos humanos, vinculados a políticas públicas, que objetivam garantir a cidadania dos seus membros. Trata-se evidentemente de um momento muito significativo na história da comunidade no país.

Atualmente tenho observado que o termo correto é LGBTQQICAPF2K+. Trata-se da sigla para Lésbicas, Gays, Bissexuais, Transexuais e Travestis, Queer, Questionando, Intersexo, Curioso, Assexuais, Pan e Polissexuais, Amigos e Familiares, Two-spirit e Kink. Ou seja, a sigla ganhou novas letras para expressar seu desejo de inclusão. Objetivando facilitar nossa compreensão e ação, informo que as letras significam o seguinte: Questionando: é uma pessoa que não sabe qual a sua identidade ou orientação sexual. Intersexo: são pessoas que nascem com genital ambíguo, com pênis, com vagina, depende de cada pessoa. Essas pessoas não se encaixam perfeitamente nas definições tradicionais de "sexo masculino" ou "sexo feminino". Curioso: é para quem tem curiosidade de experimentar outras coisas, mesmo tendo certeza do que é. Assexual: é para todas as pessoas que não sentem atração sexual, ou seja, o sexo não faz parte de um relacionamento. Pansexual e polissexual: alguém que sente atração independentemente do gênero da pessoa e polissexual é quem sente por vários gêneros, mas não todos. Familiares e Amigos: também conhecido como aliados. São pessoas que se consideram parceiras da comunidade. Two-spirit: é uma identidade indígena americana, bastante antiga, que não possui o padrão de gênero da sociedade como homem e mulher. Eles acreditam ter nascido com espíritos masculino e feminino dentro delas. Kink: significa 
fetiche, ou seja, simplesmente pessoas com fetiches. Esses grupos tem se organizado ao longo do tempo e se constituído em movimento pelos direitos civis das pessoas que se identificam com um desses termos.

É evidente que existam questionamentos e dúvidas, mas a compreensão do movimento é incorporar o maior número de pessoas com suas identidades sexuais. Nem sempre esses grupos estão de acordo com as denominações, entretanto, é possível observar esses comportamentos em nossos ambientes escolares, familiares e eclesiais. A sociedade civil acolhe todas estas formas de ser e de amar. Vem ganhando cada vez mais visibilidade a presença de pessoas LGBTQIA+ nos diversos âmbitos da sociedade, o que expressa o fruto da luta destes grupos vulneráveis contra uma cultura opressiva e, muitas vezes, violentas. A atual postura de aceitação da sociedade, apesar das ainda presentes resistências, é fruto de uma luta que não pode ser desconsiderada e ainda está longe do fim. A violência e o preconceito, frutos de um comportamento patriarcalista e, homofóbico com raízes fortes em nossa cultura, produziu a ignorância, a aversão e o medo, contra as pessoas dessa comunidade, taxando-as de portadoras de doenças, imorais, criminosas e outros adjetivos pejorativos que visam denegrir a imagem de pessoas pela orientação sexual que possuem.

O Dia Internacional do Orgulho LGBT é comemorado todo dia 28 de junho. Ele relembra a Revolta de Stonewall, em Nova York, no ano de 1969. Durante seis dias, membros da comunidade saíram às ruas lutando pelos seus direitos! No Brasil, o movimento LGBT ganhou força na década de 70, em pleno auge da Ditadura Militar (1964-1985). A luta é longa, ainda hoje, milhares de gays, lésbicas e travestis sofrem violências em suas famílias domésticas, expulsos de suas casas, e muitos ainda perdem a vida, por conta da falta de leis que protejam a comunidade. Entretanto, existem conquistas sociais importantes que visam à proteção e a inclusão de pessoas pertencentes à comunidade LGBTQIA+ em todos os âmbitos da sociedade. A grande barreira retardadora desta luta, especialmente no Brasil, ainda é a religião e a cultura, que agindo conjuntamente e de diversos modos, insistem em manter as margens pessoas com orientação sexual diferenciada do padrão heteronormativo. 
A falta de uma legislação especifica, enquadra o crime de LGBTfobia, no Brasil, aos crimes raciais. Desde 1989 o racismo é considerado crime no Brasil e é expressamente proibida qualquer veiculação de propaganda ou símbolos que façam apologia a crimes raciais, tais como símbolos nazistas ou de supremacia branca. O crime racial vem ganhando espaço na discussão pública, pois, o racismo e outras expressões de preconceito contra a identidade de uma pessoa em sua totalidade, têm sido percebidos como um problema que foge à ordem do particular e se enraíza na cultura e na estrutura social Brasileira.

Além das siglas e dos nomes, existe um movimento social para que essas pessoas sejam reconhecidas em sua dignidade e possam viver felizes com suas famílias. A convivência com essas pessoas e ou casais é uma realidade em nossa vida cotidiana. Muitos deles são oriundos da tradição católica, foram batizados, crismados, fizeram a primeira comunhão e querem ter participação eclesial ${ }^{4}$. A participação eclesial é um fator de inclusão e de reconhecimento de suas dignidades pessoais. 0 preconceito, fruto da ignorância que produz a violência deve se combater com um novo estilo de vida e uma nova educação dos costumes (sexualidade). Iniciativas sociais na área da educação, do direito, das religiões e da justiça devem ser valorizadas para que a sociedade alcance evolução maior.

\section{Famílias em transe: realidade social e magistério}

Podemos observar que o contexto familiar vem passando por profundas transformações, tanto em sua estrutura, quanto em suas funções. Existe uma nova compreensão do papel das famílias na sociedade civil. As transformações inerentes as novas concepções e técnicas de procriação (fertilização in vitro), redução do número de filhos, mudanças econômicas e políticas, emancipação da mulher, uso de pílulas, métodos contraceptivos diversos, novas condições de trabalho, estudos, vida social e, tantos outros, tem produzido mutações importantes. São muitas as situações que apontam

${ }^{4}$ TRASFERETTI, J. A. Pastoral com homossexuais: retratos de uma experiência. Petrópolis: Vozes, 1995. 
para mudanças profundas e radicais no contexto familiar. 0 magistério entende como situações difíceis ou irregulares: matrimônios mistos, matrimônios à experiência, uniões livres, casados apenas civilmente, separados e divorciados recasados ou não. Compreendem-se ainda, os que vivem sem vínculo institucional. Na verdade, o magistério, incentiva o matrimônio considerado legitimo e procura compreender as situações sociais (econômicas, políticas, culturais) que dificultam a construção da família no formato do matrimonio conjugal (jurídico e sacramental).

As problemáticas elencadas pela reflexão eclesial, normalmente restringem-se às uniões heterossexuais. Pensa-se sempre em relações heterossexuais, colocando à margem uma infinidade de outros modelos de relações e expressões de amor. Quase nenhuma palavra para os relacionamentos homoafetivos. Daí a importância dos argumentos que colocam em evidência as novas formas de uniões no contexto da comunidade LBGTQIA+. As novas formas de relacionamento amoroso (homoafetividade) não supõe, evidentemente, uma ameaça à vida familiar, tal como o magistério ensina, mas mudanças de comportamento, que colocam sob nova perspectiva outras formas de constituição familiar norteadas pelo mesmo amor que une os casais heterossexuais. É preciso abertura, acolhimento, tolerância democrática e capacidade de conviver com situações diferentes numa cultura que ainda prima pelas relações heterossexistas e patriarcalistas ${ }^{5}$. Trata-se de uma mudança de mentalidade e comportamento cultural no âmbito da sexualidade.

Voltando o nosso olhar à vida pastoral e religiosa cristã, observamos que a Doutrina Social da Igreja católica condiciona a vida sexual ao contexto do matrimonio (jurídico e sacramental) enquanto disposição para a constituição da família (união e procriação), dentro do contexto da lei moral natural ${ }^{6}$. Existem muitos movimentos de casais presentes em nossas Dioceses e Comunidades Paroquiais que se pautam por estas orientações (Encontro de Casais com Cristo (ECC), Movimento Familiar Cristão (MFC), Equipes de Nossa Senhora (ENS), Famílias Novas (Focolarinos), Famílias de Caná, e, tantos

\footnotetext{
${ }^{5}$ TRASFERETTI, J.A.; LEERS. Homossexuais e Ética Cristã. Campinas: Átomo, 2002.

6 VIDAL, M., Moral Cristã em tempos de relativismos e fundamentalismos. Aparecida: Santuário, p. 139-142.
} 
outros. Estes movimentos, ou organizações que objetivam atuar junto aos casais constituídos oficialmente segundo as orientações do magistério católico, defendem certa imutabilidade no comportamento sexual e familiar, em vista da preservação dos ensinamentos tradicionais do magistério, não considerando o desenvolver dos tempos e a necessidade de uma coerente adaptação que torne o magistério mais próximo ao evangelho.

Os documentos do magistério são inúmeros e bem constituídos lançando a base moral do comportamento familiar no contexto da heterossexualidade. No contexto atual muitas famílias não constituídas oficialmente (jurídico e sacramental) participam normalmente ou procuram nossas comunidades para atendimentos pessoais ou sacramentais. A consciência comum do povo de Deus em sua totalidade, ou seja, aqueles conscientes e aprofundados na fé cristã e aqueles que a vivem de maneira tradicional e superficial, não levam em grande conta o ensinamento magisterial em relação ao matrimonio e a família. Há uma distancia entre o que é ensinado e o que é vivido. Tal distancia é percebida pelo Papa Francisco em seu ministério o leva a convocar uma nova postura pastoral em relação às singulares condições da contemporaneidade. Consideramos que é preciso atender a todos sem julgamentos ou preconceitos, especialmente no que diz respeito à questão sacramental, como nos orienta a Exortação Apostólica Póssinodal do Papa Francisco, Amoris Laetitia no capítulo 8.

Os novos comportamentos em contexto de homoafetidade, ou mesmo as uniões heterossexuais, que não obedecem à moralidade da união civil e, do sacramental, não são considerados como “família” no sentido teológico, nem recebem a devida atenção das paroquias e seus párocos, porque não se pautam pelos elementos morais que a doutrina eclesial aponta (caráter não natural, falta de complementariedade afetivo-sexual, abertura a transmissão da vida, etc). Entretanto, podemos considerar que as uniões de fato, casais estáveis, coabitação, união, convivência familiar, normalmente estão fundamentadas no amor que os une e, nos traços humanísticos que os caracterizam. As formas de configurações familiares que não se encaixavam no contexto da doutrina do magistério, não eram consideradas dentro da realidade pastoral. Estas formas eram desconsideradas, isoladas, 
marginalizadas e condenadas ao nada.

O Teólogo Moralista José Trasferetti, escrevendo sobre a lógica inclusiva do evangelho, afirma: “no mundo atual, é difícil encontrar uma paroquia ou mesmo uma pastoral específica que não congregue em seu seio pessoas oriundas do mundo LGBTQI+. Todos os párocos e coordenadores de alguma pastoral precisam saber lidar com essa situação. Se em tempos atrás era algo "mais tranquilo", pois se marginalizava e pronto, hoje não podemos mais agir assim. Tampouco devemos ignorar e fingir que não é conosco. É preciso abrir os olhos e desenvolver atitudes pastorais que acolham essas pessoas e seus familiares"7.

Segundo O Papa Francisco, na Exortação Apostólica Pós-sinodal “Amoris Laetitia”,

O sínodo referiu-se a diferentes situações de fragilidade ou imperfeição. A este respeito, quero lembrar aqui uma coisa que pretendi propor, com clareza, a toda a igreja para não nos equivocarmos no caminho: duas lógicas percorrem toda a história da lgreja: marginalizar e integrar. (...). O caminho da Igreja, desde o Concílio de Jerusalém em diante, é sempre o de Jesus: o caminho da misericórdia e da integração. (...). 0 caminho da Igreja é o de não condenar eternamente ninguém; derramar a misericórdia de Deus sobre todas as pessoas que a pedem com coração sincero (...). Porque a caridade verdadeira é sempre imerecida, incondicional e gratuita. Por isso, é preciso evitar juízos que não levam em consideração a complexidade das diversas situações e é necessário prestar atenção ao modo como as pessoas vivem e sofrem por causa da sua condição ${ }^{8}$.

A integração de pessoas da comunidade LGBTQIA+ pela Igreja emerge na contemporaneidade como um paradigma que interpela o núcleo da própria fé. Seguir o caminho de Jesus, que com afirma o Papa Francisco, é seguir um caminho de integração, acolhida e misericórdia, coloca a Igreja em uma profunda necessidade de reflexão acerca de sua postura concreta. Por vezes, se constata que muitos casais homoafetivos sentem-se profundamente excluídos da comunidade cristã em vista do modo como o ensinamento oficial

\footnotetext{
7 TRASFERETTI, 2020, p. 331-332.

8 PAPA FRANCISCO. Amoris Laetitia. Brasília: Edições CNBB, 2015, n. 296. 
é expresso. A comunidade cristã é responsável por integrar ou marginalizar?

A presença dessas pessoas em nossas "famílias", locais de trabalhos, ao redor da vizinhança, comunidades eclesiais têm produzido certo embaraço. Não se trata de um tema fácil, pois nossas famílias, escolas, amigos, comunidades não sabem muito bem como lidar com essas pessoas, seja em suas individualidades ou nas formas unitivas e ou de acasalamento que estão envolvidas. O preconceito, fruto da ignorância é muito grande. Esse preconceito tem produzido no Brasil e em muitos países uma grande violência (física, moral, psicológica) contra estas pessoas e suas instituições ${ }^{9}$. É preciso oferecer educação moral em todos os ambientes da sociedade civil para compreender a situação e acolher as pessoas dessas comunidades numa convivência civil, fraterna e saudável.

A cultura e a própria estrutura social e religiosa perpetuam ideias de preconceito e discriminação. Não somente o catolicismo, mas outras denominações cristãs enfatizam ordens de condenação às pessoas homossexuais. Muitas dessas pessoas vivem em situação de relacionamento familiar. Não se trata evidentemente do conceito de família e matrimônio como entende o magistério (jurídico e sacramental), mas no sentido amplo da palavra em termos de compromisso, solidariedade, valores cristãos de respeito e harmonia. Os pastores podem e devem reconhecer valores cristãos presentes nesses ambientes e oferecer o devido acompanhamento, orientação, discernimento e integração. É preciso educar a comunidade para acolher e integrar essas pessoas ou casais ${ }^{10}$.

A Igreja católica por meio dos seus documentos deixa claro que a sexualidade deve ser vivida em contextos da heterossexualidade, pois se faz presente a transmissão da vida (procriação). Entretanto, podemos dizer que essas novas experiências amorosas de união civil, também possuem valores que devemos respeitar. Muitos acasalamentos vivem de forma séria, são respeitosos, educam os filhos corretamente, são honestos, vivem a dimensão do amor ágape de forma plena. Os novos relacionamentos vivem o conceito de fecundidade em outra dimensão, a dimensão do amor que ultrapassa

\footnotetext{
${ }^{9}$ TRASFERETTI, J.A. Deus por onde Andas? Campinas: Alinea, 1999.

10 TRASFERETTI, J.A. Teologia e Sexualidade: um ensaio contra a exclusão moral. Campinas: Átomo, 2004.
} 
fronteiras e gera comportamentos de respeito, cuidado e paz ${ }^{11}$. Podemos dizer, ainda, que muitos matrimônios cristãos constituídos no civil e no religioso nem sempre se mantem fiéis respeitosos e dignos. Não se trata de se apegar ao rigor doutrinal, mas a vida concreta com seus comportamentos reais no cotidiano da existência.

Os novos acasalamentos amorosos, mesmo os de configuração homoafetiva, podem ser considerados famílias, não no sentido jurídico/sacramental, mas no sentido afetivo, pois no amor imenso que os congrega sobressaem-se os valores que os aproximam do evangelho. Eu mesmo conheço muitas pessoas que se comportam como famílias: criam laços de amor, são respeitosos, favorecem o diálogo fraterno, frequentam suas igrejas. É preciso saber compreender e fazer as devidas distinções de comportamento. A violência e a injustiça estão presentes na vida dos casais homo e heterossexuais, bem como, a bondade e a justiça.

As uniões homoafetivas constituem-se num novo modelo de comportamento. Às vezes, tem sido criticado por aqueles que defendem uma família onde prima o caráter institucional e, não a dinâmica do amor em sua complexidade afetiva. Quando o Estado não acolhe nem regulamenta a união homoafetiva, ele está deixando de proteger as pessoas envolvidas nesta nova configuração amorosa. Quando o Estado não protege a união homoafetiva como "família" ele está negligenciando as pessoas envolvidas, deixando de cumprir o seu papel de promotor do bem comum, em sua pluralidade de costumes e vidas.

Segundo Matéria publicada no site da UOL/Universa por Mariana Gonzalez em 04/05/2021 04h00, quase 80 mil casais LGBTQIA+ formalizaram sua relação nos últimos dez anos, desde quando o Brasil entrou para a (ainda seleta) lista de países que reconhece a união civil entre duas pessoas do mesmo sexo. Segundo esta reportagem entre 2011 e 2020, o número de registros de união estável de casais homoafetivos passou de 1.531 para 2.125, e o de casamentos, de 3.700, para 8.472 - um aumento de $28 \%$ e $138 \%$, respectivamente -, segundo levantamento da Anoreg (Associação dos Notários

11 ZACHARIAS, R., Repensando a Moral Sexual. In: ZACHARIAS, R., CASTRO MILLEN, M.I., A Moral do Papa Francisco: um projeto a partir dos descartados. Aparecida: Santuário, 2020, p. 283-330. 
e Registradores do Brasil) feito exclusivamente para o site UOL/Universa. Já se completaram dez anos que o Supremo Tribunal Federal (STF), decidiu por unanimidade, equiparar os direitos de casais homoafetivos aos direitos de casais heterossexuais e reconhecer como família a união entre dois homens ou duas mulheres e os filhos do casal. Segundo essa mesma matéria, em 2018, o número de registros teve uma alta de $61 \%$ em relação a 2017 , com uma influência política: a eleição do presidente Jair Bolsonaro. Ao reconhecer a união de pessoas do mesmo sexo, o Supremo Tribunal Federal (STF) possibilitou uma série de outros avanços favoráveis à população LGBTQIA+: a união civil em 2013; o nome social para pessoas trans, em 2016; a criminalização da homofobia e da transfobia, em 2019; e a permissão para doar sangue, em 2020.

Entretanto, todas essas decisões foram tomadas pelo Poder Judiciário, e não pelo Legislativo, portanto, não são leis e nem direitos conquistados. Na verdade, são avanços que precisam ser ampliados e configurados em sua prática cotidiana. A conquista maior para a comunidade LGBTQI+ será quando - Congresso Nacional se tornar sensível a essa parcela da população e transformar essa decisão judicial em lei que altere o Código Civil, favorecendo as famílias brasileiras. A violência, o preconceito, contra casais homoafetivos ou pessoas em sua individualidade, ainda estão fortemente presentes na cultura brasileira. E a maneira de se combater determinados costumes socialmente enraizados nasce de uma nova forma de educar, nas qual atua simultaneamente a consciência de uma legislação protetora dos mais vulneráveis.

O documentário, "Francesco", dirigido pelo americano Evgeny Afineevsky, foi exibido pela primeira vez no Festival de Roma. Nesse documentário o Papa Francisco disse que casais homoafetivos devem ser protegidos por leis de união civil. Segundo muitos analistas a fala foi a declaração mais forte já dada por um pontífice em defesa dos direitos LGBT. O Papa Francisco afirmou, nesse documentário, que pessoas homossexuais são filhos de Deus e, têm o direito de estar em uma família. Ninguém deveria ser descartado [dela] ou ser transformado em miserável por conta disso. O Papa Francisco tem sinalizado por meio de palavras e gestos o desejo de que a 
comunidade LGBTQI+ seja acolhida e integrada na sociedade civil e em nossas Comunidades Eclesiais Missionárias. Tendo em vista que as relações homossexuais são criminalizadas em muitos países, não se trata evidentemente de uma situação fácil. Entretanto, é possível por meio de pequenos gestos e palavras. Acolher e orientar essas pessoas e, ou casais possibilitando uma vida digna plena de direitos e cidadania, tal como deseja e incentiva o Papa Francisco.

\section{Bondade pastoral: orientação moral segura}

Toda pessoa humana é filha de Deus. Esta máxima orienta a reflexão e a ação da Igreja, o que implica em um acolhimento respeitoso e amoroso independentemente de sua orientação sexual, cor, religião, natureza, etc. Se antigamente nossas paroquias, estavam atentas somente aos solteiros, namorados, noivos, famílias (matrimonio juridicamente constituído), hoje é preciso abrir o leque e acolher, acompanhar e, orientar outras pessoas com a mesma dignidade (recasados e outras formas de "convivência familiar", que estejam fundamentadas no amor, vivam a reciprocidade amorosa, o respeito civil dentro da tolerância e, da boa convivência).

O fato de não ter o documento jurídico do matrimonio, não significa que devemos abandonar, isolar, condenar a própria sorte. A comunidade eclesial também tem a sua responsabilidade. Dentro do processo indicado pela Encíclica Apostólica Pós-sinodal Amoris Laetitia (sobre o amor na Família) publicada pelo Papa Francisco em 2016, após longa consulta popular, encontramos uma rica orientação pastoral que objetiva acolher, educar, discernir e, integrar as fragilidades. Solicita-se ainda a compreensão amorosa com as situações conjunturais e, os fatores atenuantes que envolvem a vida de qualquer pessoa. Casais homoafetivos possuem uma história e uma situação que devem ser compreendidas. 0 julgamento preconceituoso deve ser evitado e o amor misericordioso e educativo deve ser praticado em nossas paroquias.

O teólogo moralista espanhol Marciano Vidal, aponta que a vida pastoral deve proceder um caminho pedagógico, que implica em três passos para os casais que convivem sem institucionalização: “1. "aproximação 
respeitosa: aproximar-se-ão dos que convivem com discrição e respeito". 2. Compreensão de cada situação: "preocupar-se-ão em conhecer tais situações e suas causas concretas, caso por caso". 3. Atuação evangélica: empenhar-seão numa ação de iluminação paciente, de correção caridosa e de testemunho familiar cristão que possa aplanar-lhes o caminho para a regularização da situação". ${ }^{12}$ Evidentemente que o Teólogo Marciano Vidal, faz referências aos casais heterossexuais, deixando em aberto a vida e prática dos casais homoafetivos. Entretanto, o mesmo caminho de compreensão, acolhimento, atuação evangélica, devem nortear a conduta dos párocos em relação a toda forma de união civil estável e comprometida.

Marciano Vidal aponta, ainda, a necessidade de uma atuação educativa. Para ele, "é decisivo o trabalho de informação e de educação sobre os favores que configuram a autêntica dimensão institucional do matrimônio". É preciso organizar um projeto educativo no qual entram como elementos decisivos: "o cultivo da fidelidade na educação moral e religiosa dos jovens"; "a instrução sobre as condições e estruturas que favorecem a fidelidade, sem a qual não se dá a verdadeira liberdade", "a ajuda para amadurecer espiritualmente", "a exata compreensão da rica realidade humana e sobrenatural do matrimônio-sacramento"13.

De todo modo existe uma questão de fundo que permeia a cultura brasileira. Trata-se da sexualidade enquanto integradora da personalidade. É preciso realizar uma revisão desse componente importante da vida humana levando em consideração as conquistas das ciências nos últimos anos e os avanços sociais produzidos pela cultura dos meios de comunicação de massa, das novas tecnologias e plataformas digitais presentes no mundo atual. 0 teólogo moralista Ronaldo Zacharias afirma: "o que humaniza a sexualidade não é o amor? É preciso que este amor seja, necessariamente, conjugal e heterossexual?"14. Diz ainda Ronaldo:

"a maturidade afetivo-sexual não se manifesta na doação (abertura) de si ao outro, no esforço para que a sexualidade

\footnotetext{
12 VIDAL, M. Moral Cristã: em tempos de relativismos e fundamentalismos: Aparecida: Santuário, 2007, p. 137.

${ }^{13}$ VIDAL, 2007, p. 138.

${ }^{14}$ ZACHARIAS, 2020, p. 297.
} 
seja cada vez menos um instrumento para usar os outros e cada vez mais uma capacidade de se doar plenamente a uma pessoa, de maneira exclusiva e generosa. No contexto do dialogo interpessoal, as relações de intimidade não contribuem para o amadurecimento integral da pessoa, amadurecimento que o conduzirá ao dom de si ao outro? Não seria mais justo falar de significado fecundo da sexualidade do que de significado procriativo". ${ }^{15}$

O questionamento do Professor Ronaldo aponta para a direção do amor que une e, da fecundidade que amplia o conceito para além do ato biológico. A humanização produzida pelo amor se estende a todas as expressões de configurações familiares, independente da formulação jurídica.

O Papa Francisco na exortação apostólica Amoris Laetitia, afirma: “Por isso, um pastor não pode sentir-se satisfeito apenas aplicando leis morais aos que vivem em situações "irregulares", como se fossem pedras que se atiram contra a vida das pessoas" ${ }^{16}$. É o caso dos corações fechados, que muitas vezes se escondem atrás dos ensinamentos da Igreja "para se sentar na cátedra de Moisés e julgar, às vezes com superioridade e superficialidade, os casos difíceis e as famílias feridas" ${ }^{17}$.

O coração do Pastor deve ir além das leis e normas, mas se aproximar do evangelho da misericórdia que sempre oferece um caminho novo de amor fraternal. Esta nova postura do coração do Pastor é orientada pela compreensão mais profunda e significativa do que seja a sexualidade, a fecundidade o amor e, até mesmo, o conceito de família.

Papa Francisco, citando a Comissão Teológica Internacional, afirma: “a lei natural não pode ser apresentada como um conjunto já constituído de regras que se impõem a priori ao sujeito moral, mas é uma fonte de inspiração objetiva para o seu processo eminentemente pastoral, de tomada de decisão"18. Continua o texto: "Por causa dos condicionalismos ou dos fatores atenuantes, é possível que uma pessoa, no meio de uma situação objetiva de pecado - mas subjetivamente não seja culpável ou não o seja plenamente -, possa viver em graça de Deus, possa amar e possa também 
413 | A questão da família na perspectiva LGBTQI+

crescer na vida de graça e de caridade, recebendo para isso a ajuda da Igreja. O discernimento deve ajudar a encontrar os caminhos possíveis de resposta a Deus e de crescimento no meio dos limites. Por pensar que tudo seja branco ou preto, às vezes fechamos o caminho da graça e do crescimento e desencorajamos percursos de santificação que dão glória a Deus"19 0 discernimento amoroso que é fruto de um longo processo de acompanhamento, fundado no amor, deve produzir frutos de vida nova para todos. É preciso olhar com os olhos do coração de Deus e abandonar os julgamentos que matam gerados por uma cultura que estimula o ódio e aversão (fobia) contra seres humanos que fazem o bem. Essas orientações devem ser compreendidas dentro de um grande leque de abertura levando em consideração os contextos atuais de união e acasalamento amoroso.

A nota 351 do documento Amoris Laetitia, afirma que "em certos casos, poderia haver também a ajuda dos sacramentos". Por isso, "aos sacerdotes, lembro que o confessionário não dever ser uma câmara de tortura, mas o lugar da misericórdia do Senhor” (EG n. 44) E de igual assinala que a Eucaristia "não é um prêmio para os perfeitos, mas um remédio generoso e um alimento para os fracos" (EG n. 47) ${ }^{20}$. O confessionário é um espaço importante na vida de uma paróquia. O pároco deverá saber acolher com o carinho necessário, a compreensão ampla, dos processos de vida que estão em andamento, promovendo sempre o bem e a conversão para Deus ${ }^{21}$. Conheci ao longo da história muitas pessoas que não foram bem atendidas nos confessionários, sofrendo a violência das palavras e dos olhares que condenam de forma antievangélica.

Do ponto de vista do magistério católico não podemos chamar de famílias estas uniões, mas, podemos reconhecer que muitos casais ou pessoas em sua singularidade podem viver um amor esponsal, em termos de doação, cuidado, fidelidade, abertura, reciprocidade, verdade, serviço. Embora vivendo em contextos chamados "irregulares", ou fora do matrimônio (família), tais casais ou pessoas não podem ser consideradas em pecado,

\footnotetext{
${ }^{19}$ PAPA FRANCISCO, 2015, n. 305.

20 PAPA FRANCISCO, 2015, nota n. 351.

${ }^{21}$ TRASFERETTI, J.A.; GOMES, A. Homossexualidade: orientações formativas e pastorais. São Paulo: Paulus, 2011.
} 
doentes ou, ainda, fora do caminho para Deus. Não podem ser excluídas, e justamente por isso, devem ser destinatárias de uma atitude de inclusão num processo gradual de crescimento da fé e da vida sacramental. Os gestos do Papa Francisco, demostram uma solicitude pastoral muito enriquecedora. Suas cartas pastorais, pronunciamentos, atitudes mostram uma solicitude pastoral de simpatia, empatia e acolhimento às pessoas e ou casais homoafetivos que praticam os valores de respeito, amor e cuidado.

Em junho de 2021, tomamos conhecimento que o Papa Francisco escreveu uma carta ao jesuíta americano James Martin para agradecê-lo por seu trabalho pastoral com as comunidades de crentes LGBT. O Papa Francisco exalta a proximidade, compaixão e ternura do Padre Martim e tantos outros para com a comunidade LGBTQI+. Na verdade, são muitas as questões teológicas que permeiam nosso cotidiano social e pastoral. Infelizmente ainda vivemos num país e numa cultura que se caracteriza em larga medida pelo patriarcalismo (machismo), LGBTQI+ fobia, racismo estrutural e corrupção sistêmica $^{22}$. Talvez no futuro não tenhamos mais que fazer distinções entre os direitos e deveres dessa comunidade e os demais direitos. As relações serão assimétricas com integração plena e inclusão afetiva.

A Conferencia Nacional dos Bispos do Brasil (CNBB) em seu documento de estudos (104), intitulado "Comunidade de Comunidades: Uma nova Paróquia”, afirma:

Em nossas paroquias participam pessoas unidas sem o vínculo sacramental, outras estão numa segunda união, e há aquelas que vivem sozinhas sustentando os filhos. Outras configurações também aparecem, como avós que criam netos ou tios que sustentam sobrinhos. Crianças são adotadas por pessoas solteiras ou por pessoas do mesmo sexo que vivem em união estável ${ }^{23}$.

O mesmo documento abordando o tema do acolhimento nos orienta o caminho, quando afirma:

\footnotetext{
${ }^{22}$ CANOSA, A.C.; ZACHARIAS, R.; KOELLER, S.MF. Sexualidades e Violências: um olhar sobre a banalização da violência no campo da sexualidade. São Paulo: Ideias\&tetras, 2019.

${ }^{23}$ CONFERENCIA NACIONAL DOS BISPOS DO BRASIL (CNBB). Comunidade de Comunidades: uma nova paróquia. Brasília: Edições CNBB, 2013, n. 101. 
A Igreja, família de Cristo, precisa acolher com amor todos os seus filhos. Sem esquecer os ensinamentos cristãos sobre a família, é preciso usar de misericórdia. É hora de recordar que o Senhor não abandona ninguém e que, também, a Igreja quer ser solidária nas dificuldades da família. Muitos se afastaram e continuam se afastando de nossas comunidades porque se sentiram rejeitados, porque a primeira orientação que receberam fundamentava-se em proibições e não em uma proposta de viver a fé em meio à dificuldade. Na renovação paroquial, a questão familiar exige conversão pastoral para não perder nada do que a Igreja ensina e igualmente não deixar de atender, pastoralmente, as novas situações familiares ${ }^{24}$.

A teologia moral está atenta a todas estas manifestações culturais e procura caminhos graduais de respeito e de integração social e eclesial. É preciso avançar na compreensão do magistério e da sociedade civil na forma de leis, de acolhimento, proteção, educação e integração nas comunidades. Podemos afirmar que as variadas formas de acasalamento amoroso ou uniões civis não se constituem numa forma de ameaça à família tradicional. É possível que todos convivam de maneira democrática e em harmonia com o criador, praticando uma teologia que faça a prevenção correta contra todas as formas de fobias ${ }^{25}$. As pluralidades de vidas, acasalamentos, dignificam e engrandecem a vida humana. Não se trata de viver o ideal pleno, mas a gradualidade das vidas em direção ao progresso amoroso que os conduz no caminho de Deus.

\section{Considerações finais}

Toda pessoa é filho de Deus. Deus ama a todos em igual dignidade. Seu olhar, seu carinho, sua misericórdia e seu amor são para todos. Independentemente da sua orientação sexual, forma de convivência familiar, cor, etc. $\mathrm{O}$ amor de Deus se estende a todos. A comunidade paroquial deve acolher com carinho, educar, proteger, discernir e integrar essas pessoas num

\footnotetext{
${ }^{24}$ CONFERENCIA NACIONAL DOS BISPOS DO BRASIL, 2013, n. 102.

${ }^{25}$ MASSINGALE, B.N. Prevenir contra a homofobia. In: TRASFERETTI, J.A.; ZACHARIAS, R.; COELHO, M.M. Teologia da Prevenção: por um caminho de humanização. São Paulo: Paulus, 2021, p. 321-358.
} 
clima de amor e de paz, respeitando a diversidade de seus comportamentos ${ }^{26}$. A atitude da comunidade paroquial é sempre reflexo da atitude do próprio Deus. Na medida em que se compreende a Igreja como presença e sacramento da Trindade no mundo, ela deve ser marcada por uma atitude de amor e misericórdia ilimitada.

Menos rigor doutrinal e mais compaixão na vida pastoral. Deus não é dado aos rigorismos. Apesar das inúmeras experiências humanas de Deus serem traduzidas em leis e costumes que orientam a vida, por vezes, e especialmente o Novo Testamento, alertou para a condição amorosa e misericordiosa de Deus que se encontra acima do rigorismo da Lei. A nova lei do amor é o sinal máximo da expressão de Deus como aquele que supera toda a justiça rigorista. Tal compreensão, porém, depende de uma renovação da consciência e da educação gradual no caminho da fé. Não se pode prescindir da tarefa da educação. A educação moral é uma tarefa do pároco e de seus colaboradores mais próximos. A educação moral consiste em apresentar de maneira sistemática o pensamento das fontes teológicas (sagradas escrituras, tradição, magistério, teologia atual) sobre o comportamento moral em tempos de transformações sociais.

A educação moral é parte intrínseca do trabalho pastoral porque combate a ignorância, favorece o respeito e o diálogo, num clima de crescimento constante. A violência gerada pelo preconceito, fruto da ignorância, só se combate com a educação, na forma mais cabal de esclarecimento, informação didática, convencimento moral. Os paroquianos precisam ser preparados para o diálogo, o estudo, o conhecimento. Se a recusa em aprender predomina, consequentemente o preconceito e a violência aumentam. Um dos grandes problemas culturais e sociais do Brasil reside na resistência à educação para uma nova cultura. Ainda está enraizada no imaginário dos jovens inúmeros estereótipos que significam masculinidade, e que comportam a agressividade, a exclusão e o autoritarismo.

A época de Jesus a cultura patriarcal, preconceituosa e fóbica também estava presente e é preciso olhar para o comportamento de Jesus de

${ }^{26}$ VIDAL, M. Sexualidade e Condição homossexual na Moral Cristã. Aparecida: Santuário, 2008. 
Nazaré diante das questões morais complexas do seu tempo, a fim de encontrarmos respostas para as questões contemporâneas. Ele soube agir e indicou um caminho possível, valido para o nosso tempo também. Do ponto de vista da benignidade pastoral a ordenação jurídica deve ficar em outro plano. É preciso saber conviver pastoralmente com todas as formas de constituição familiar (não somente aquela ordenada juridicamente como pressupõe a moral cristã). É preciso fortalecer a bondade pastoral, em todas as instancias de acolhimento: educação, discernimento, proteção e integração. 0 modo pastoral (pastoralidade) indica o caminho moral a ser seguido, como orientação precisa em novos caminhos de uma igreja cada vez mais em saída. O teólogo moralista Ronaldo Zacharias, apresenta esse caminho de uma forma pratica e criativa ${ }^{27}$.

É preciso manter o ideal proposto do matrimonio e da família constituído de forma jurídica e sacramental, mas ao mesmo tempo agregar, integrar em nossas comunidades outras formas de relacionamento amoroso que possuam virtudes morais do amor, do respeito, da delicadeza. É preciso, ainda, combater a violência (física, moral, psicológica) seja entre casais hetero ou homo, e promover a inclusão, a integração de todas as formas de amor. As estatísticas que atestam o desequilíbrio afetivo (ampliado pela pandemia) e o feminicídio, e outras formas de violências domésticas, têm aumentado fortemente em nosso país. A educação para o amor (sexualidade) é o maior caminho das pastorais em tempos atuais, e esta é uma tarefa para todos os batizados, independente dos serviços que cada um assumiu em sua comunidade.

$\mathrm{Na}$ verdade, podemos até observar que em nosso contexto eclesial existe uma contradição prática, ou seja, igrejas cristãs que deveriam ser sacramentos de humanização amorosa acabam legitimando discriminações e violências. As pessoas da comunidade LGBTQIA+ são bem vindas porque possuem valores reais que se aproximam do evangelho de Jesus de Nazaré em sua praticidade real, histórica e cotidiana. Elas também colaboram com a humanidade ao assumir a diversidade de gêneros como contribuição à fraternidade humana que o Papa Francisco apresenta na Carta encíclica

${ }^{27}$ ZACHARIAS, 2021.

Fronteiras, Recife, v. 4, n. 2, p. 398-420, jul./dez., 2021 
Fratelli Tutti (sobre a fraternidade e a amizade social), publicada em 2020. ${ }^{28}$ Nesse sentido, podemos afirmar que seria muito bom se nossas comunidades paroquiais soubessem reconhecer, respeitar e valorizar a identidade sexual e a orientação de gênero de todas as pessoas. Cada uma delas merece ouvir os ministros de Jesus os/as chamarem de filhos e filhas, como Jesus chamou aquela mulher curada e agora integrada na comunidade. As pessoas humanas, reunidas em forma de família ou não, possuem direitos civis, eclesiais e sexuais ${ }^{29}$. Mais ainda: todos os teólogos moralistas nos tempos atuais concordam que é preciso renovar a Moral Sexual de forma ampla e profunda. A doutrina do magistério católico sobre a sexualidade precisa ir além da normatividade e da heterossexualidade. É preciso avançar para águas mais profundas, tarefa de todos os batizados, em tempos de póspandemia $^{30}$.

\section{Referências}

CANOSA, A.C.; ZACHARIAS, R.; KOELLER, S. M. F. Sexualidades e Violências: um olhar sobre a banalização da violência no campo da sexualidade. São Paulo: Ideias\&Letras, 2019.

CONFERENCIA NACIONAL DOS BISPOS DO BRASIL (CNBB). Comunidade de Comunidades: uma nova paróquia. Brasília: Edições CNBB, 2013.

CORREIA LIMA, L. (Org.) Teologia e Sexualidade: portas abertas pelo Papa Francisco. Rio de Janeiro: Educam/Editora reflexão/ Centro Alceu Amoroso Lima, 2015.

GENOVESI, V. J. Em busca do Amor: moralidade católica e sexualidade humana. São Paulo: Loyola, 2008.

JUNG, P. B., CORAY, J.A. Diversidade Sexual e Catolicismo: para o desenvolvimento da teologia moral. São Paulo: Loyola, 2005.

\footnotetext{
${ }^{28}$ PAPA FRANCISCO. Fratelli tutti (sobre a fraternidade e a amizade social). São Paulo: Paulus, 2020.

${ }^{29}$ ZACHARIAS, R., Ética e Direitos Sexuais. São Paulo: Ideias\%Letras, 2021.

30 ZACHARIAS, R., Amoris Laetitia: Um 'sim' radical à Pastoralidade da Teologia Moral. Perspectiva Teológica., Belo Horizonte, v. 53, n.1. 17-39, jan/abr. 2021. 
JUSTO, G. Pelo $12^{\circ}$ ano consecutivo, Brasil é o país que mais mata transexuais no mundo. In: Exame, 2020, disponível em < https://exame.com/brasil/pelo12o-ano-consecutivo-brasil-e-pais-que-mais-mata-transexuais-no-mundo/ > Acesso em: 16/08/2021.

FLORES, G. Matrimônio e Família. São Paulo: Paulinas, 2008.

PAPA FRANCISCO. Amoris Laetitia. Carta Encíclica pós-sinodal. Brasília: edições CNBB, 2015.

TRASFERETTI, J. A. A Lógica Inclusiva do Evangelho. In ZACHARIAS, R., CASTRO MILLEN M.I. A Moral do Papa Francisco: um projeto a partir dos descartados. Aparecida: Santuário, 2020.

TRASFERETTI, J.A., LEERS. Homossexuais e Ética Cristã. Campinas: Átomo, 2002.

TRASFERETTI, J.A. Deus por onde Andas? Campinas: Alínea, 1999.

TRASFERETTI, J.A. Teologia e Sexualidade: um ensaio contra a exclusão moral. Campinas: Átomo, 2004.

TRASFERETTI, J.A.; GOMES, A. Homossexualidade: orientações formativas e pastorais. São Paulo: Paulus, 2011.

TRASFERETTI, J.A.; ZACHARIAS, R.; COELHO, M.M. Teologia da Prevenção: por um caminho de humanização. São Paulo: Paulus, 2021.

VIDAL, M. Moral Cristã em tempos de relativismos e fundamentalismos. Aparecida: Santuário, 2007.

VIDAL M. Matrimonio: entre o ideal cristão e a fragilidade humana. Aparecida: Santuário, 2007.

VIDAL, M. Sexualidade e Condição homossexual na Moral Cristã. Aparecida: Santuário, 2008.

ZACHARIAS, R. Amoris Laetitia: Um “sim' radical à Pastoralidade da Teologia Moral. Perspectiva Teológica, Belo Horizonte, v. 53, n.1. 17-39, jan/abr. 2021.

ZACHARIAS, R.; CASTRO MILLEN M.I. A Moral do Papa Francisco: um projeto a partir dos descartados. Aparecida: Santuário, 2020. 
ZACHARIAS, R. Ética e Direitos Sexuais. São Paulo: Ideias\&Letras, 2021.

ZACHARIAS, R.; CANOSA, A.C.; KOEHLER, S.M.F. Sexualidades e Violências. São Paulo: Ideias\&Letras, 2019.

Trabalho submetido em 10/09/2021.

Aceito em 21/12/2021.

José Antônio Trasferetti

Doutor em Teologia Moral, Pontifícia Universidade Lateranenses (Roma, 1990), reconhecido pela Pontifícia Universidade Católica do Rio de janeiro em 1996. Doutor em Filosofia pela Pontificia Universidade Gregoriana (Roma, 1994), reconhecido pela Universidade de São Paulo (USP) em 2010. Bolsista do CNPq na Europa/Itália (19891991) e do Bischofliche Aktion Adveniat entre 1987 a 1991 e 1993. Email: trasferetti@uol.com.br 